\title{
The energy future of Saudi Arabia
}

\author{
Alberto Boretti ${ }^{1, *}$, Stefania Castelletto $^{2}$, Wael Al-Kouz ${ }^{1}$, Jamal Nayfeh $^{1}$ \\ ${ }^{1}$ Mechanical Engineering Department, College of Engineering, Prince Mohammad Bin Fahd University, Al Khobar, Saudi Arabia \\ ${ }^{2}$ School of Engineering, Royal Melbourne Institute of Technology (RMIT) University, Bundoora, Victoria, Australia
}

\begin{abstract}
In a recent publication, North European experts argue that "Saudi Arabia can achieve a 100\% renewable energy power system by 2040 with a power sector dominated by PV single-axis tracking and battery storage". They also say "Battery storage contributed up to $30 \%$ of the total electricity demand in 2040 and the contribution increases to $48 \%$ by 2050". Based on considerations specific to the geography, climate conditions, and resources of Saudi Arabia, it is explained as batteries and photovoltaic solar panels are not the best choice for the country's energy sector. To cover all the total primary energy supply of Saudi Arabia by solar photovoltaic, plus battery storage to compensate for the sun's energy intermittency, unpredictability, and seasonal variability, is impracticable and inconvenient, for both the economy and the environment. Better environment and economy may be achieved by further valorizing the fossil fuel resources, through the construction of other high-efficiency plants such as the combined cycle gas turbine plants of Qurayyah, development of novel technologies for the production of clean fuels and clean electricity, including oxyfuel combustion and carbon capture and storage. Construction of nuclear power plants may also be more beneficial to the economy and the environment than photovoltaic and batteries. Regarding solar energy, enclosed trough solar thermal power systems developed along the coast have much better perspectives than solar photovoltaic, as embedded thermal energy storage is a better approach than battery storage. Further, a centralized power plant works better than distributed rooftop photovoltaic installations covered by dust and sand, rusted or cracked. Finally, pumped hydro energy storage along the coast may also have better perspectives than battery storage.
\end{abstract}

\section{Introduction}

A recent paper [1] by North European academics of title "The role that battery and water storage play in Saudi Arabia's transition to an integrated $100 \%$ renewable energy power system” has claimed that “... Saudi Arabia can achieve a $100 \%$ renewable energy power system by 2040 with a power sector dominated by PV single-axis tracking and battery storage. Single-axis tracking $P V$ contributed $210 \mathrm{GW}$ out of the total $403 \mathrm{GW}$ by 2040. The contribution increased to $369 \mathrm{GW}$ out of a total of 520 GW by 2050. Battery storage contributed up to $30 \%$ of the total electricity demand in 2040 and the contribution increases to $48 \%$ by 2050." Apart from the use of past tense for the future, batteries do not produce electricity. They only store the electricity produced by something else for later use. Additionally, battery energy storage is still in its infancy, and not a proven off the shelf technology, and it has significant economic, environmental, sustainability, and ethical costs in the present offer that imped their widespread use worldwide. Regarding the source of the energy that the batteries may store for future release, it is hard to believe that this energy can be produced by solar photovoltaic (PV). They are much less efficient and much more expensive than it is portrayed. Additionally, they suffer from specific issues in Saudi
Arabia such as sand and dust that dramatically increases the costs and reduces the performances over time.

Opposite to what it may be supported by a general narrative as reported in papers such as [1] where "Saudi Arabia can achieve a $100 \%$ renewable energy power system by 2040 with a power sector dominated by PV single-axis tracking and battery storage", here based on a technical basis, we explain why this is simply impracticable and not convenient.

PV systems still have significant costs and work with average capacity factors of about $0.27-0.28$ in much better environments such as Australia if power facilities, or as low as 0.10 average capacity factors if distributed solar rooftop [2], [3], [4], [5]. In Saudi Arabia, dust and sand drastically reduce efficiency as well as the lifetime and require expensive cleaning systems.

The capacity factors of individual facilities also suffer from coefficients of variability more than unity due to intermittency and unpredictability [2], [3], [4]. Even at the country average level, intermittency and unpredictability are huge, as the solar resource is never available at night time and seasonality affects every installation.

Battery storage is only in its infancy. The world's largest battery, adopted also in Australia, only has 100

\footnotetext{
* Corresponding author: a.a.boretti@gmail.com
} 
MW of nominal power and 140 MWh of nominal energy storage [2]. For system stability, it is never charged or discharged above $30 \%$ nominal power, thus it is only charged and discharged at a small fraction of the storage capacity.

Based on their life cycle assessments, the use of wellestablished combined cycle gas turbines plants is superior under every criterion, i.e. economic, environmental, ethical, sustainability, that the technically dubious use of battery storage and PV systems.

If Saudi Arabia is targeting a better environment and a low carbon energy economy, it would be better to invest in nuclear for baseload, while fostering more efficient use of fossil fuels through high-efficiency plants such as combined cycle gas turbine plants. Cleaner uses of fossil fuels [6] is also an opportunity to explore.

Regarding solar, enclosed through solar thermal power systems developed along the coast have much better perspectives than solar PV.

Concerning the opportunity to also use pumped hydro energy storage, also suggested by a similar generic narrative, [1] claim, "The role that battery and water storage play in Saudi Arabia's transition to an integrated $100 \%$ renewable energy power system", it must be remembered that Saudi Arabia has no rivers and extraordinarily little water. While traditional hydropower in other countries may certainly be converted to pumped hydro by adding pumping capabilities [2], albeit often selling the hydro generating power on demand twice, Saudi Arabia has no existing hydropower facilities.

Coastline pumped hydro is still in its infancy, with so far, a single small demonstration plant built, run for few years, and then quickly decommissioned in Japan.

Not working yet technologies should not be overrated to diminish well established viable technologies.

As a further contribution to support our arguments, here we survey as a case study the operation of real-world PV and battery energy storage systems in the only country where high-frequency data is made available to the public, Australia. The Australian national electricity market (NEM) is an open system where operators and traders buy and sell electricity with transparency. The Australian NEM data is reproduced from ref. [7].

\section{Materials and methods}

The data energy production from ref. [7] is available every 5 minutes - daily data - or 3 hours - monthly data, in terms of power or capacity factor. The capacity factor is the ratio of the actual generating power to the registered capacity. The total registered capacity of solar facilities (all PV) is 3,427 MW. The data of ref. [8] is available every 30 minutes for the daily graphs and every 3 hours for the monthly graphs. The total registered capacity of the solar rooftop is about 8,000 MW. The data of ref. [9] is available every 5 minutes - daily data - or 3 hours monthly data, as power or capacity factor. The total registered capacity of battery energy storage is $191 \mathrm{MW}$.

\section{Results}

High-frequency data of solar resources, weather conditions, and power plant components and system output are necessary to design the energy storage needed to produce a stable grid fed by intermittent and unpredictable wind and solar energy. To accurately validate and make reliable renewable energy software tools systems design, they must be based on high frequency (every minute or less) accurate weather data and plant data, with this latter both at the system, as well at the components level.

Fig. 1 presents one sample day solar PV power supply to the grid in amid-summer day in Australia, and the use of the battery storage, plus the grid demand. Data in [7], [8], [9] and [10] are also available monthly every month of the year but with a 3 hours resolution. The grid demand is between 18.5 GW at 3:00 and it will peak well above $30 \mathrm{GW}$ between 15:00 to 18:00. Only the power delivered by the battery to the grid is reported by the National Electricity Market Operator. The power absorbed by the battery is shown over the 24 hours in graphs on the web site of the facility operator, but it is not available as tabulated data to download.

Fig. 2 presents the statistic of the capacity factor of one PV solar facility (Broken Hills, NSW, Australia) during the year 2018. As also discussed in [3], The capacity factors oscillate between 0 and 1. Nighttime is zero. Daytime approaches 1 . The mean capacity factor is 0.27 . The standard deviation of the capacity factor is 0.37 . The coefficient of variability is more than unity at 1.37 .

Fig. 3 presents the measured solar power from distributed rooftop panels every month of one year from February 2019 to January 2020. To be considered, the installed capacity increased by more than $25 \%$ over the year. Roughly, the delivered capacity factors were around 0.10 [2], [3], [4], [5].

In principle, the power above the average, without support by facilities of controllable output such as combustion fuel facilities, must be stored for later release in the energy storage. The power, in defect of the average, must be released by the energy storage system. This has to be ensured not at the plant level, but the grid level. However, it is expected that plants with a larger coefficient of variability contribute more to the cost of the grid energy storage that somebody must pay. Electricity produced when not needed and not produced when needed is a major issue that must be finally accounted for.

Over the 24 hours, the grid demand is approaching 600 GWh of energy, but the grid supply by solar facilities and rooftop is less than $60 \mathrm{GWh}$. This means that 10 times larger installed capacity by solar would be necessary to fully cover the power demand of the grid during a cloudless sky, peak irradiance, mid-summer day. Then, there are also days with clouds, and rain, and there is also not the only summer, but also spring/autumn and winter, but we neglect this aspect for the sake of simplicity.

Regarding the battery energy storage needed, it would be much more than the $192 \mathrm{MW}, 0.192 \mathrm{GW}$, of the nominal power now available. As the actual maximum charge and discharge, power is less than one-third of the registered capacity, the registered power needed by battery storage would be several hundred times larger, and even larger would be the requirement of energy to be 
stored. Batteries will have indeed to collect a huge amount of extra solar energy during the daylight times to release during the night times.

Here we only considered battery storage. Australia has some, despite limited, pumped hydro capabilities. Australia has few rivers and mountains, and more water than Saudi Arabia despite being a mostly arid land. Pumped hydro is a quick solution to rapidly increase the energy storage capability of a country, despite selling twice the same hydropower. Apart from the round-trip efficiency extremely far from unity and much worse than the batteries, pumped hydro does not help too much in Saudi Arabia. Saltwater pumped hydro may be a better choice, but it must be proved first to work, before starting huge investments in potentially risky technologies. The renewable energy world is full of unaccomplished projects that never produced the expected outcomes.

Regarding saltwater pumped hydro, the $30 \mathrm{MW}$ Okinawa Yanbaru Seawater Pumped Storage Power
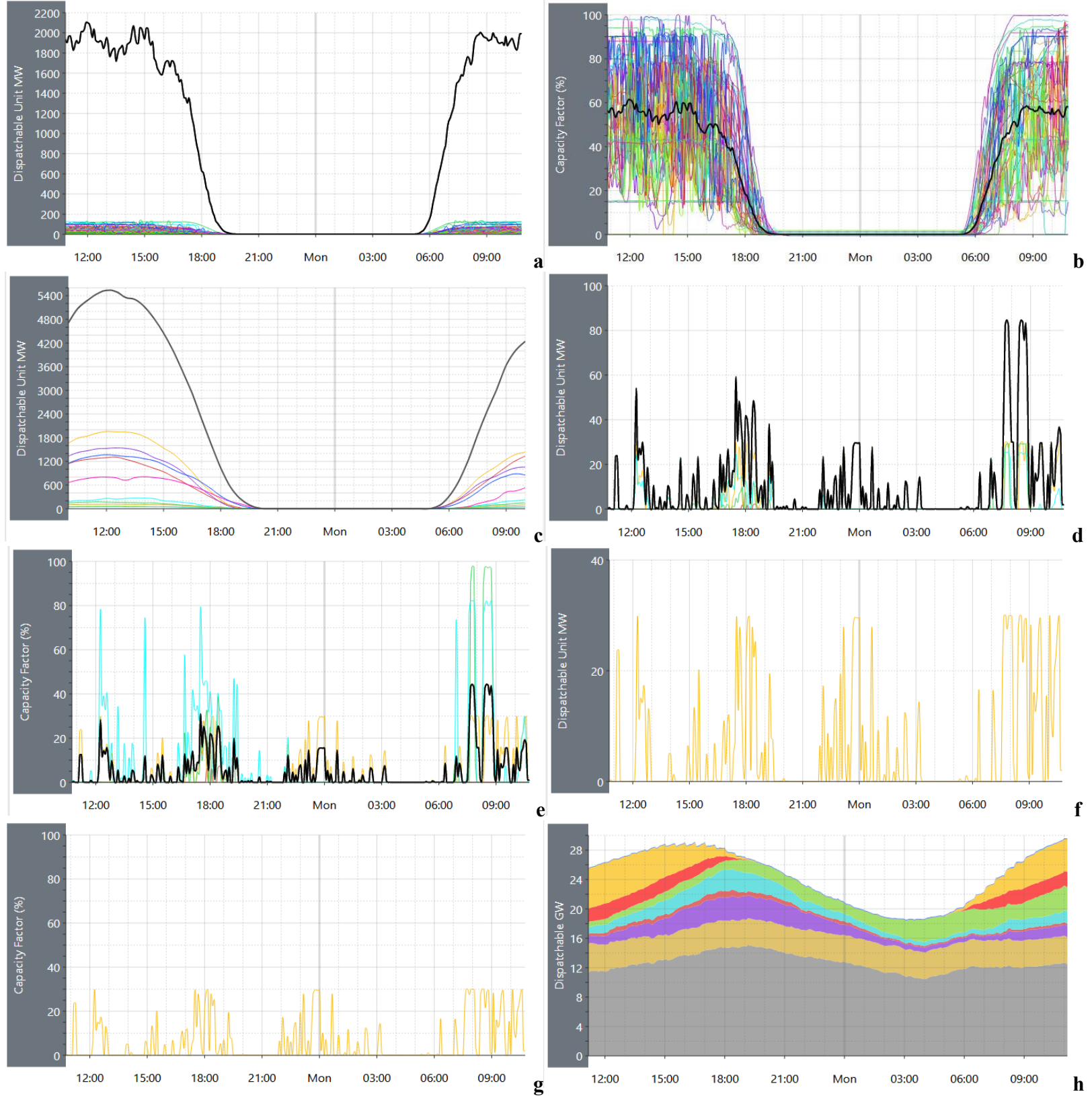

Fig. 1 - Measured power and capacity factors of all the PV facilities, rooftop PV, and battery storage connected to the Australian National Electricity Market Grid, over a sample 24 hours' time window. 24-hours' time window, ending 10:AM December 30, 2019. 
Images reproduced modified from [6], [7] and [8]. (a) and (b) power and capacity factors of solar facilities with 5 minutes of resolution. Individual facilities' contributions shown. The tick black line is the grid average. The registered capacity is 3,427 MW. (c) power of solar rooftop with 30 minutes of resolution. Individual states and sub-states zones' contributions shown. The tick black line is the grid average. Registered capacity is more than $8,000 \mathrm{MW}$. (d) and (e) power and capacity factors of battery energy storage facilities 5 minutes of resolution. Individual facilities' contributions shown. The tick black line is the grid average. The registered capacity is 192 MW. (f) and (g) power and capacity factors of Hornsdale battery energy storage facility. 5 minutes of resolution. The registered capacity is $100 \mathrm{MW}$. (h) power demand by the grid. Explanation of colors of the different contributors to the present energy mix in [10].
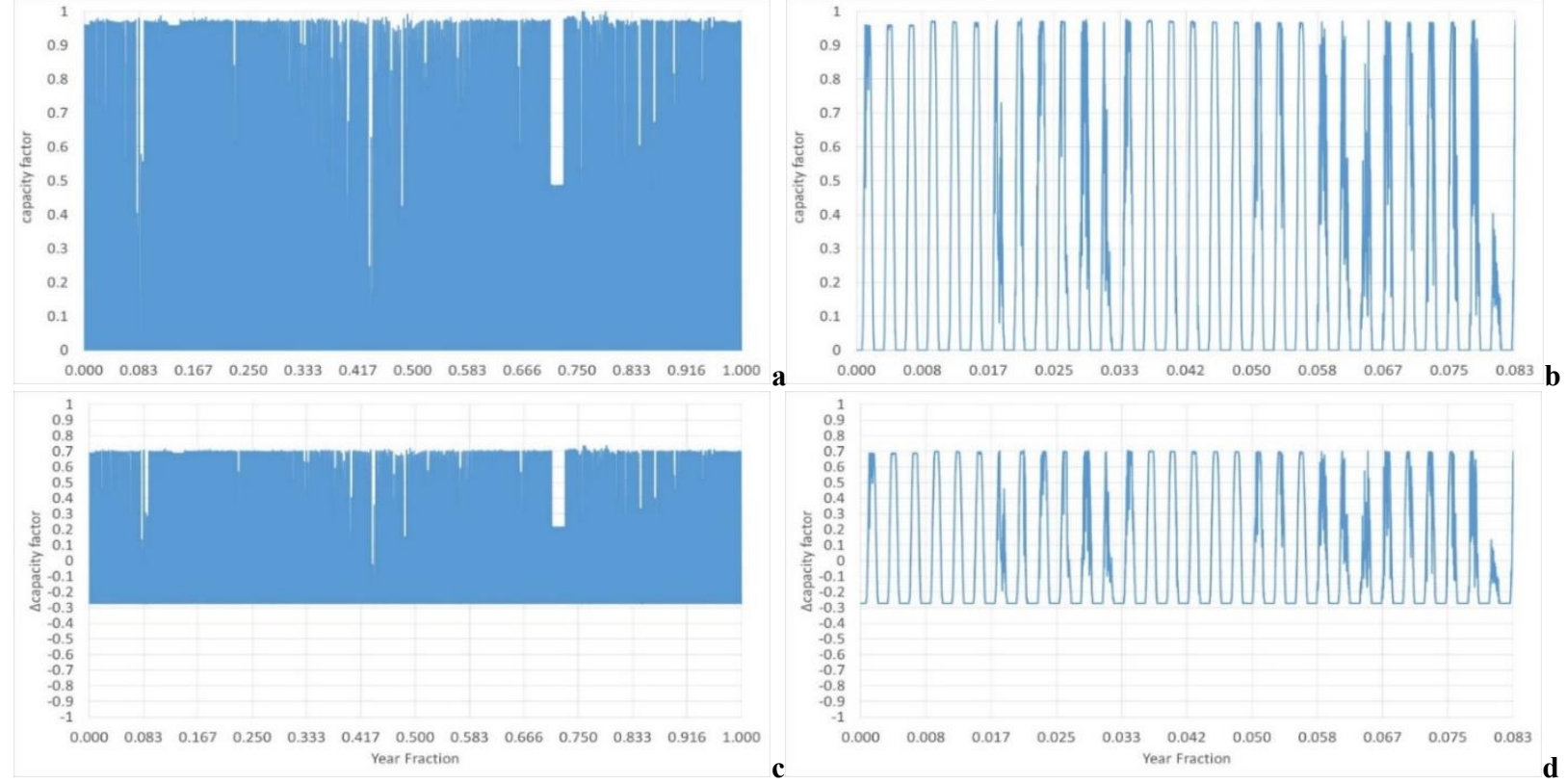

Fig. 2 - (a) and (b) Measured capacity factors of the 54.5 MW Broken Hills PV facility in NSW, Australia during the full year 2018 and January 2018. The capacity factors oscillate between 0 and 1 . Nighttime is zero. Daytime approaches 1 . The mean capacity factor is 0.27 . The standard deviation of the capacity factor is 0.37 . The coefficient of variability is more than unity at 1.37 . (c) and (d) Differences vs. the annual mean value over the year 2018 and January 2018. The power more than the average must be stored for later release in the energy storage. The power less-than-the-average must be released by energy storage. This has not to be ensured at the plant level, but at the grid level. However, it is expected that plants with a larger coefficient of variability contribute more to the grid energy storage.
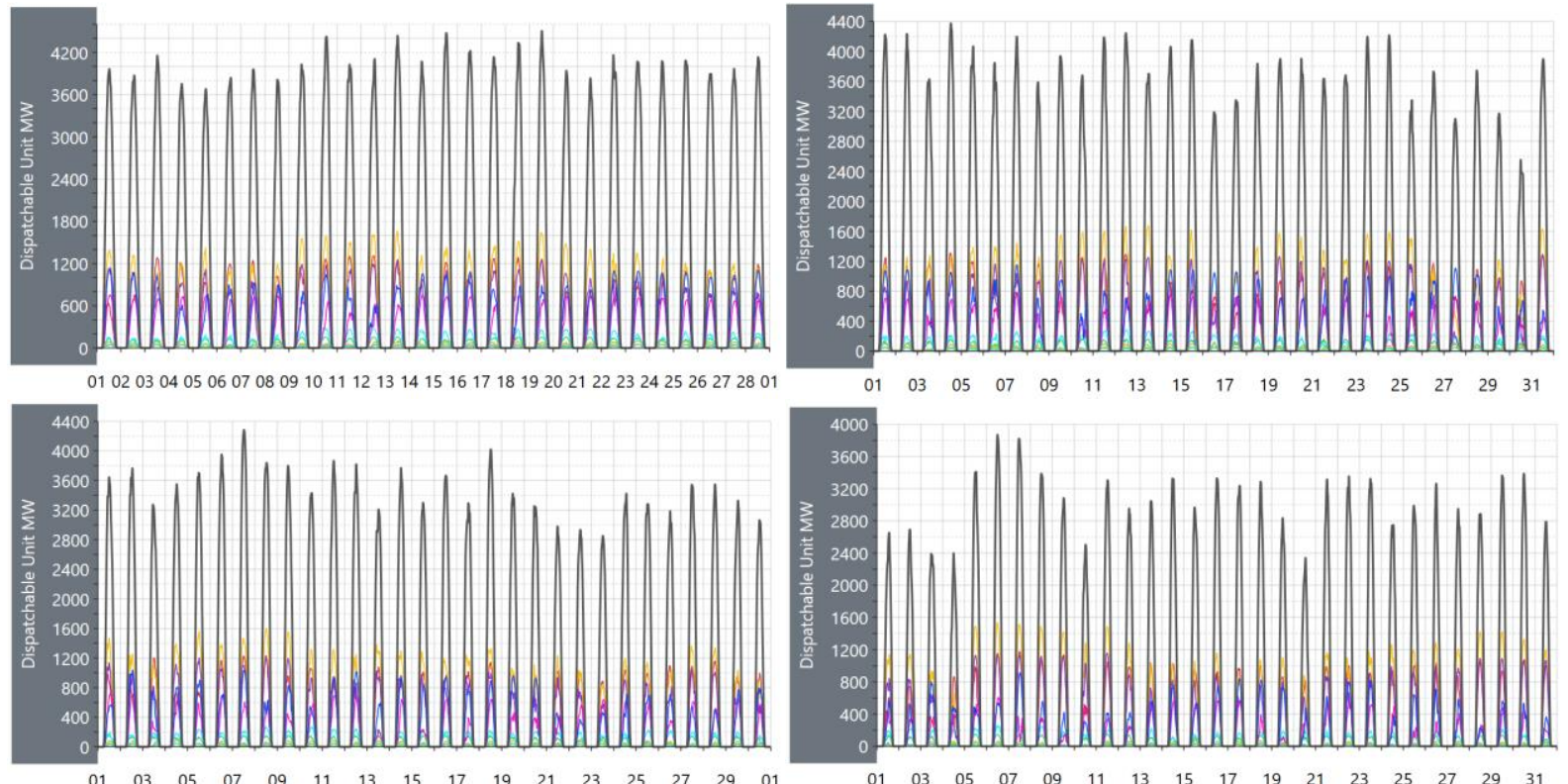

Fig. 3 - continues. Measured solar power from distributed rooftop panels every month of one year from February 2019 to January 2020 (moving top to bottom, left to right). Images reproduced modified from [8]. Over the year, the total installed capacity has dramatically increased, as the trend 2017 to 2020 is to double the capacity [11], which is a $25 \%$ increased capacity over the year. While an accurate statistic is almost impossible, it may be estimated that the rooftop solar panels work with an average capacity factor of about 0.10 . 

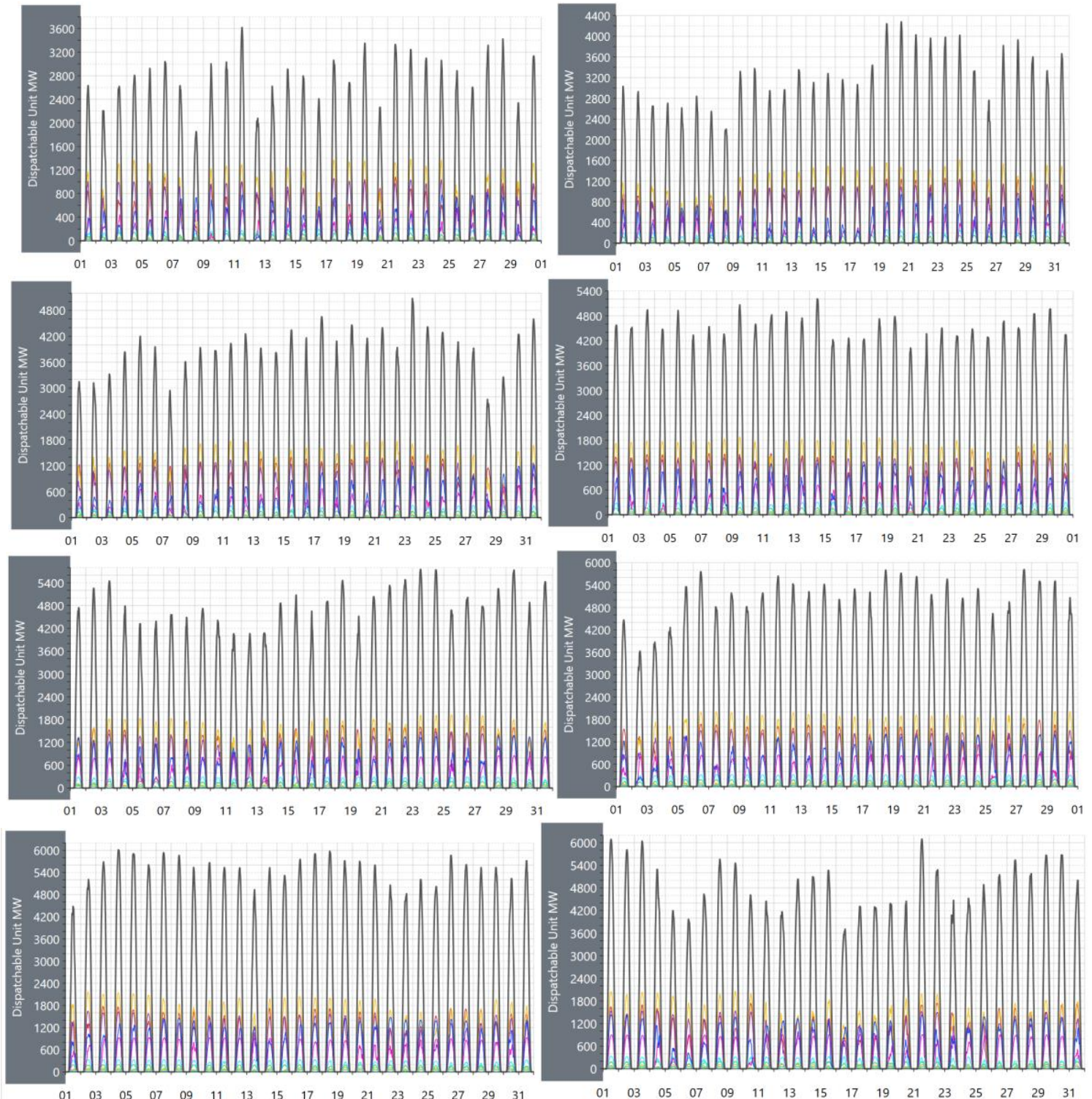

Fig. 3 - continued. Measured solar power from distributed rooftop panels every month of one year from February 2019 to January 2020 (moving top to bottom, left to right). Images reproduced modified from [8].

\section{Discussion and Conclusions}

The noble quest for a future "without reliance on oil" (and coal and natural gas) should not forget what is technically possible and what it is not. Higher shares of renewable energy only make sense if they produce better economic and environmental outcomes.

It is an unfortunate circumstance that highly optimistic but not realistic expectations are proposed in many renewable energy papers. Ref. [1] is just one of the examples of the many. Not less questionable is, for example, the press release [12] about the paper [13], published the first of April 2019, that places 530,000 potential pumped-hydro sites worldwide, including the aridest, deserts of the world, such as the Sahara or the Simpson desert or the empty quarter in Saudi Arabia, where there is no water, there are no upper and lower reservoirs, there are no electricity grids, there are no people and there are no renewable energy facilities in need of stabilization.
More wind and solar energy are possible only once the energy storage issue has been properly addressed and resolved. There is no product available off the shelf to address the energy storage issue.

The total primary energy needs of a country are not limited to the small electricity production but are much more. The global primary energy needs of an expanding world are difficult to be covered by present-day solar, wind technologies, and battery storage.

The world's largest battery storage (Hornsdale Power Reserve, in Australia) is only $100 \mathrm{MW}$ of power. It is only used in charge and discharge at $30 \%$ of this nominal power. It is charged and discharge not the full energy of $140 \mathrm{MWh}$, but much less. The charging and discharging is made to maximize the profits of the operator, buying cheaper energy and selling more expensive energy, and not to stabilize a grid.

Additional to power, the storage must be designed also for energy. 
As solar is only available during daylight time, there is simply not enough raw material in this world, to make possible a sun energy powered planet.

It is similarly unclear where the equally huge energy needed to build the batteries would come from, as we may risk running out of fossil fuels to produce the electricity needed to build the solar panels and the batteries.

To build the batteries needed to store for later release 12 hours a day the excess energy produced by solar in the other 12 hours is huge demand (we neglect for simplicity the differences between summer and winter solar resource).

Partisan claims should consider basic mathematics of what is needed to make dreams come true before being aired as feasible alternatives to today's solutions.

Solar PV and battery energy storage is not the future of Saudi Arabia, simply because it is impossible to achieve $100 \% \mathrm{PV}$ and battery storage coverage of the total primary energy needs of the country, and this is also not convenient for both the economy and the environment.

Both the economy and the environment call for a much better solution. These are a better use of fossil fuels, with cleaner production of electricity and fuels, and investment in nuclear energy.

Regarding the uptake of solar, that due to the intermittency always need the back-up of traditional power plants at significant costs if the energy storage issue is not solved first, enclosed through coastal installations have much better perspectives than inland or coastal PV systems.

Once industrialized, enclosed through systems may cost less, produce more, and have a much longer lifetime than PV systems. Not by chance plants such as SEGS in the US are still working with acceptable capacity factors despite having been built in the 1980s, well above the expected life span.

It never pays to invest in questionable novel technologies while downplaying better viable technologies.

It is necessary to invest in more research and development of better technologies for use fossil fuels, further improve nuclear technologies, and study better renewable energy production and storage systems. The purchase of foreign-built solar panels and Li-ion batteries may be a partisan interest of Northern European countries, but it will not produce any improvement to the economy nor the environment of Saudi Arabia or the rest of the world.

It must be added that Concentrated Solar Power has in Saudi Arabia a much better perspective than PV. The advantages compared to PV are dispatchability, higher annual average capacity factor, a reduced standard deviation of the capacity factor, and production of electricity after sunset [5], [14], [15].

Solana, which features the well-established and reliable parabolic trough technology, with 6 hours of molten salt thermal energy storage, has already reasonable costs. The 250 MW plant, completed in 2013, had a construction cost of 2 billion \$US. This translates into a CAPEX of $8,000 \$ U S / \mathrm{kW}$. The capacity factor of Solana is also increasing, presently at $36.4 \%$. Working 25 years at this capacity factor translates into a cost of 0.100
US $\$ / \mathrm{kWh}$. By adding the O\&M cost of $33 \$ / \mathrm{kW} / \mathrm{yr}$., this translates into a final cost of $0.1100 \mathrm{US} \$ / \mathrm{kWh}$. By introducing mass production for a further improved design, the cost of electricity could be easily be brought down well below the values for PV that already enjoy mass production. Worth to mention, 25 years of life are very optimistic for PV plants, but concentrated solar power plants may work much longer (see the SEGS plants still operational even if built in the 1980s, [5]).

PV not only needs batteries. Additionally, for the specific application in Saudi Arabia in general, but $\mathrm{Al}$ Khobar in particular, enclosed trough with once trough saltwater condenser suffer much less of sand, dust, humidity, salt, and extreme temperatures than PV. PV in Saudi Arabia in general and Al Khobar in particular dramatically suffer from the many issues, [16], [17], [18], that are preventing their uptake.

The panels collect much less solar energy being quickly covered by a layer of dust, that is converted to less electricity also because of the high temperature. Additionally, failure of the panels occurs due to rust and cracks.

There is an urgent need for quality assurance of the claims of renewable energy studies, that are becoming day by day more and more unrealistic, as well as to support the better technologies that are needed in the real world.

A plant such as the gas and fuel oil-fired combined cycle power station of Qurayyah, of fuel conversion efficiency $52 \%$, may operate with very large capacity factors almost unity. The 4,000 MW plant had a construction cost of 2.85 billion \$US. Considering the rooftop installations of Saudi Arabia are certainly not expected to deliver better capacity factors than in Australia, due to dust and sand, humidity, and extreme summer temperatures, the total nominal power of not less than $40,000 \mathrm{MW}$ of solar rooftop, coupled to battery storage of same actual power, and actual energy more than 40,000 $12=480,000 \mathrm{MWh}$, would be needed.

Considering $25 \mathrm{~kW}$ of solar power has presently a cost of 74,000 US\$ in the much cheaper US [19], 40,000,000 $\mathrm{kW}$ of solar power would cost much more than 2,960 billion \$US, which is 1,000 times more than Qurayyah, with additionally the reduced lifetime and the larger O\&M costs. Qurayyah has a fuel cost. However, with oil prices at 50 US\$ per barrel, and Saudi Arabia the world's largest oil producer, this does not change that much the economic content even before tackling the battery issue. In the US, the latest costs of electricity [20] are $0.02386 \mathrm{US} \$ / \mathrm{kWh}$ nuclear, $0.0356 \mathrm{US} \$ \mathrm{kWh}$ generic fossil steam, and $0.03243 \mathrm{US} \$ / \mathrm{kWh}$ generic gas turbine and small scale. With a capacity factor of 0.1 , a very optimistic 15 years' lifespan of the panels, and no failure, no penalty for dust and sand coverage, no cost for cleaning, the 2,960 billion \$US for 40,000,000 kW of solar power are already almost 10 times more, $0.23 \mathrm{US} \$ / \mathrm{kWh}$.

Considering the world's largest battery is only 100 MW of power and $140 \mathrm{MWh}$ of energy, but it only works with charge and discharge power up to $30 \mathrm{MW}$ and never from full-charge to zero-charge, there are clear technological issues to make possible the solar PV plus batteries replacement of just Qurayyah. Additionally, there are not only the unaffordable economic costs but 
also the unaffordable environmental costs of building and disposing of the present technology's batteries that make this solution unattractive. Present technology Li-ion batteries have indeed many energetic, environmental, sustainability, and societal issues, [21], [22] and [23], that simply should not be hidden.

It must be also remembered that the world's largest battery of Hornsdale is presently only used for trading purposes, to maximize the profit of their owners buying and selling electricity on the open market, without any goal of stabilizing a grid.

To start with small scale deployments of technologies to understand their real potentials, without overrating their pros while hiding the cons, will certainly permit a better solution for the energy needs of a country. Solar may certainly be a contributor to the energy mix of Saudi Arabia, with the right technologies, and in the right amount.

\section{Acknowledgments}

The authors did not receive any funds and have no conflict of interest to declare.

\section{Authors contributions}

$\mathrm{AB}$ sourced and analyzed the data and wrote the draft of the manuscript. S.C., W.A., and J.N. discussed the results and contributed to the writing of the definitive version of the manuscript.

\section{References}

[1] Caldera, U., and Breyer, C., 2018. The role that battery and water storage play in Saudi Arabia's transition to an integrated $100 \%$ renewable energy power system. Journal of Energy Storage, 17, pp.299-310.

[2] Boretti, A., 2019, Energy storage needs for an Australian National Electricity Market grid without combustion fuels, Energy Storage. Energy Storage. First Published: 6 October 2019. DOI:10.1002/est2.92

[3] Boretti, A., High-frequency standard deviation of the capacity factor of renewable energy facilities part 1: solar photovoltaic, Energy Storage. First Published: 21 October 2019.

DOI:10.1002/est2.101

[4] Boretti, A., High-frequency standard deviation of the capacity factor of renewable energy facilities part 2: wind, Energy Storage. Energy Storage, Volume 1, Issue 6, 2019, e100.

DOI:10.1002/est2.100

[5] Boretti, A., Cost, and Production of Solar Thermal and Solar Photovoltaics Power Plants in the United States, Renewable Energy Focus. 26:93-99 (2018). doi.org/10.1016/j.ref.2018.07.002

[6] Boretti, A. Perspectives of production of hydrogen for export from wind and solar energy, natural gas, and coal in Australia, International Journal of Hydrogen Energy, in press.

[7] anero.id/energy/solar-energy/

[8] anero.id/energy/rooftop-solar-energy

[9] anero.id/energy/battery-storage-energy

[10] anero.id/energy

[11] aemo.com.au/energy-systems/electricity/nationalelectricity-market-nem/nem-forecasting-andplanning/forecasting-and-planning-data/nemelectricity-demand-forecasts/2017-electricityforecasting-insights/key-component-consumptionforecasts/rooftop-pv-and-battery-storage

[12] www.anu.edu.au/news/all-news/anu-finds-530000potential-pumped-hydro-sites-worldwide

[13] Lu, B., Stocks, M., Blakers, A. and Anderson, K., Geographic information system algorithms to locate prospective sites for pumped hydro energy storage. Applied Energy, 222, pp.300-312 (2018).

[14] W. Al-Kouz, J. Nayfeh, and A. Boretti, Enclosed trough concentrated solar power plant with thermal energy storage and once-through saltwater condenser in Al-Khobar, Saudi Arabia, Energy Storage.

[15] W. Al-Kouz, J. Nayfeh, and A. Boretti, Design of a parabolic trough concentrated solar power plant in Al-Khobar, Saudi Arabia, 6th International Conference on Renewable Energy Technologies (ICRET 2020). Perth, Australia, January 8-10, 2020.

[16] Al-Bashir, A., Al-Dweri, M., Al-Ghandoor, A., Hammad, B. and Al-Kouz, W., Analysis of Effects of Solar Irradiance, Cell Temperature and Wind Speed on Photovoltaic Systems Performance. International Journal of Energy Economics and Policy, 2020, 10(1), pp.353-359.

[17] Al-Kouz, W., Al-Dahidi, S., Hammad, B. and AlAbed, M., Modeling, and analysis framework for investigating the impact of dust and temperature on PV systems' performance and optimum cleaning frequency. Applied Sciences, 2019, 9(7), p.1397.

[18] Nader, N., Al-Kouz, W., and Al-Dahidi, S., Assessment of Existing Photovoltaic System with Cooling and Cleaning System: Case Study at AlKhobar City. Processes, 2020, 8(1), p.9.

[19] news.energysage.com/how-much-does-theaverage-solar-panel-installation-cost-in-the-u-s/

[20] www.eia.gov/electricity/annual/html/epa_08_04.ht $\mathrm{ml}$

[21] www.amnesty.org/en/latest/news/2019/03/amnestychallenges-industry-leaders-to-clean-up-theirbatteries/

[22] www.wired.co.uk/article/lithium-batteriesenvironment-impact

[23] www.nsenergybusiness.com/features/lithium-ionbattery-environmental-impact/ 